\title{
Effects of Tandem Side-by-side GTAW Welds on Centerline Solidification Crac- king of AA2024
}

\begin{abstract}
Abdulaziz Albannai ${ }^{1}$, Abdulkareem Aloraier ${ }^{1}$, Ayman Alaskari ${ }^{1}$, Meshal Alawadhi ${ }^{1}$, Suraj Joshi ${ }^{2}$
${ }^{1}$ Department of Manufacturing and Welding Engineering Technology, College of Technological Studies, PAAET, Shuwaikh 70654, Kuwait City, Kuwait. E-mail: ai.albannai@paaet.edu.kw; as.aloraier@paaet.edu.kw; am.alaskari@paaet.edu.kw; my.alawadhi@paaet.edu.kw

2Department of Mechanical and Industrial Engineering, Concordia University, 1515 St. Catherine Street West, Montréal, Québec, Canada. E-mail: suraj.joshi@concordia.ca
\end{abstract}

Welding techniques such as gas tungsten arc welding (GTAW) can induce solidification cracking owing to the wide solidification temperature range. Riveting or mechanical fastening are plausible alternatives, but can create problems like material loss, overall weight increase, corrosion, and introduction of high stress concentration areas. This study proposes a new welding method to improve and minimize centerline solidification cracking in GTAW called "tandem side-by-side GTAW welds". AA2024 is fusion welded using GTAW, and its solidification cracking behavior is investigated and compared for two weld pool motions (straight and weaving) and the proposed method. The fishbone test was used to assess centerline solidification cracking susceptibility. The results of welding AA2024 autogenously proved that the tandem weld pool motion is superior to the other two GTAW methods. As a result, the proposed method showed lower stress concentration areas by forming less concave weld shapes, lower heat input, formation of preferable grain size and orientation thus shorter centerline solidification crack lengths with a tortuous crack path motion obtained in comparison with the straight and weave.

Keywords: Tandem Side-by-Side; Gas Tungsten Arc Welding; Centerline Solidification Cracking; AA2024; Weld Pool Motion

\section{Introduction}

Fusion welding processes join materials by melting and solidifying them through application of a hightemperature heat source to the desired joint location for a specific time. Such processes work locally to melt the material, allowing the various elements to mix with one another for alloy formation after solidification. During solidification process complicated interactions between the interface dynamics and the heat/mass transfer process take place, which lead to formation of complex solid/liquid interface morphology. Thus, dynamic solidification behavior and related issues have to be understood for optimization of the welding process and improvement of microstructure. The solidification morphology starts from the fusion line of the weld pool with changing of the grain structure from planar to cellular, columnar dendritic and mostly ends by equiaxed dendritic in the weld centerline, as is seen in Fig. $1[1,2]$. Hot cracks like solidification cracking can form and propagate during the solidification process at the trailing end of the moving weld pool in a mushy zone, where liquid is still present around the growing dendrites following the heat source [3, 4]. The mushy zone forms the area behind the weld pool during the fusion process and fills between the liquid weld metal and the solidified weld metal, which is known as a semisolid and mechanically weak zone [5]. Thus, solidification cracking phenomena is a result of the interaction among the coherent solid dendrite bridges, liquid flow, and both mechanical and thermal stresses in the mushy zone $[5,6]$.

One of the most significant problems affecting fusion welding processes during solidification process is centerline solidification cracking, a type of hot cracking encountered in welding [7, 8]. Thus, designers and engineers must avoid using fusion welding to join materials susceptible to this type of cracking. As shown in Fig. 2, centerline solidification cracking usually occurs along the solidified grain boundaries at the center of the welded metal (fusion zone) in the mushy zone specifically, when the tensile stress accumulated around the adjacent solidified grains exceeds the strength of the inter grain boundaries during the appearance of thin liquid films $[2,9]$. When tension is induced by solidification shrinkage and thermal contraction during fusion welding process, a solidification cracking forms [6, 9]. Lippold [8] stated that solidification cracking can usually be minimized or eliminated by reducing the level of thermal and/or mechanical restraint in the presence of a crack-susceptible microstructure. Therefore, solidification cracking depends on the competition between the material's resistivity to this behavior and the mechanical driving 
forces resulting from the thermal cycle around the weld pool $[8,10]$. If the mechanical driving forces exceed the material's resistivity during the terminal stage of solidification, a crack is formed in the mushy zone $[11,12]$. Consequently, solidification cracking can be a major restriction to fusion welding of aluminum alloys (AAs) having a low-melting-point $\mathrm{Al}-\mathrm{Cu}-\mathrm{Mg}$ eutectic, which are thus known an unweldable alloys [13] and hard to be weld by fusion welding processes [14] because it is susceptible to solidification cracking [15]. One of these alloys is AA2024, which is widely used in the aerospace industry because of its high strengthto-weight ratio [16]. Regrettably, AA2024 has high solidification crack susceptibility because of its $\mathrm{Cu}$ and $\mathrm{Mg}$ content and high thermal expansion [17], and as stated by Çam and İpekoğlu [18] arc welding is difficult with AA2024 and is therefore known as super duralumin.

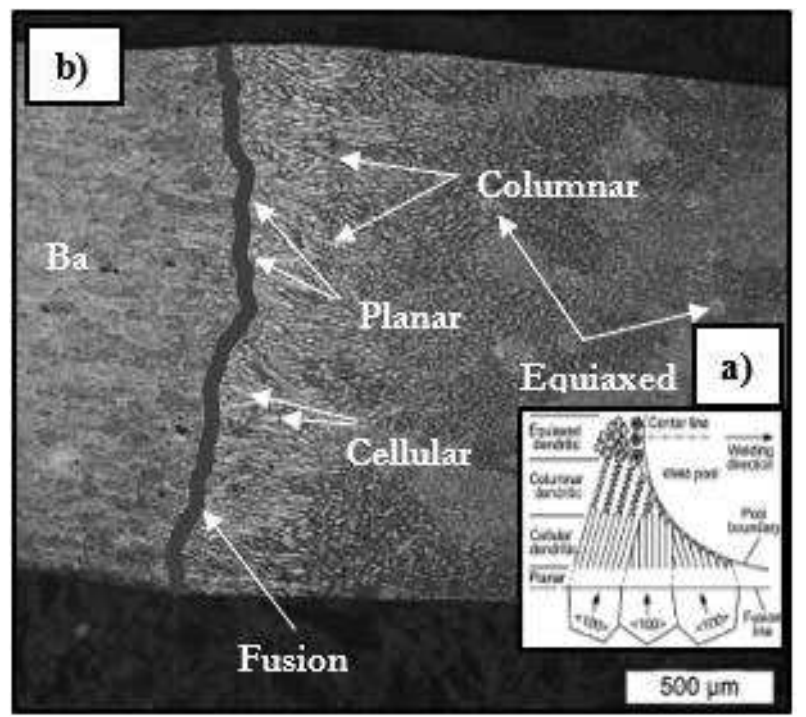

Fig. 1 (a) The solidification morphology and grain structure during a fusion welding $[1,2]$, (b) image of solidified weld pool in $A$ A2024

Several factors contribute to centerline solidification crack susceptibility in a welded material. For example, Pumphrey and Jennings [19] and Alizadeh et al. [11] indicated that a wider solidification temperature range corresponds to weaker material resistivity against centerline solidification cracking, because this wide range contributes to the formation of a low-melting-point eutectic on the grain boundaries. Moreover, Kou [20] found that higher thermal expansion of the material induces the mechanical driving forces to exceed the material's centerline solidification crack resistivity, causing cracks to form behind the weld pool (mushy zone) on the weld zone centerline because of the resultant highly localized strain as is evident in Fig. 2. Cross [21] also stated that if the solidification temperature range of a material is extended, the liquid films will be exposed to more strain, and there will be a higher likelihood for hot cracking to occur due to critical strain influence. Coniglio and Cross [22], and Pumphrey and Jennings [19] pointed out that alloys with more brittle behavior and resistance to strain in the mushy zone can result in hot cracking, where large number of secondary dendritic arms are trying to bond with each other under surrounding strains during the final stage of solidification process.

The mushy zone is the trailing area behind the weld pool and is a mechanically weak region, where interference exists between the solid and liquid phases due to competing material ductility and the strain rate of the solidification process $[5,6,23,24]$. Therefore, the mushy zone size is significant and is an effective factor in mitigating or surging material susceptibility to centerline solidification cracking. Agarwal et al. [6] observed that applying the same heat input when welding two different steel materials separately produced two different mushy zone sizes, wherein the longer one exerted high solidification cracking susceptibility due to longer solidification time and lower critical strain rate on the grain boundaries. Wang et al. [24] supported that by studying the effect of dual side-by-side laser beam welding on aluminum alloys and found that a maximum mushy zone width could be obtained with higher inter beam spacing, and that it produced a higher risk of cracking due to longer time spent under transverse strains during the solidification process.

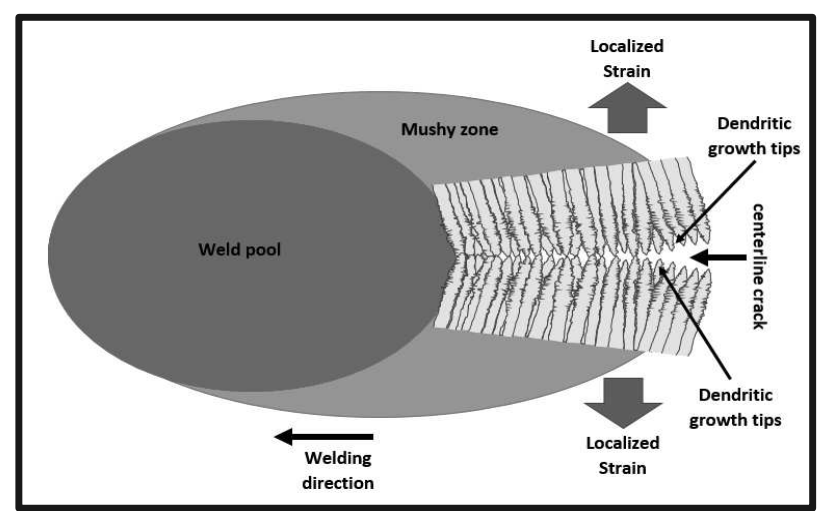

Fig. 2 Schematic of a weld pool and localized strain on the trailing edge in the mushy zone

Coarser grain size formation in the weld zone also subsidizes to centerline solidification crack initiation and propagation, whereas a finer grain size increases material crack rezistivity $[25,26]$. A finer grain size corresponds to a significantly greater boundary area, with high back filling liquid flow and more effective healing of incipient cracks during solidification [27, 28]. In contrast, a coarser grain size produces greater segregation of low melting points on the grain boundaries, allowing the localized strain to easily reach the critical point to initiate a crack $[29,30]$.

The heat input and cooling rates also play significant role in centerline solidification crack resistivity during a fusion weld process. Therefore, heat input and cooling rate may increase or decrease the risk of 
initiation and/or propagation of a crack depending on the rate of resultant accumulated strains around the semi-solidified grain boundaries [18, 31-34]. For example, Kou and Le [26] showed that longer centerline solidification cracks occur by applying higher heat input and lower cooling rate due to the higher resultant thermal stress. Ragavendran and Vasudevan [35] also stated that higher heat input produces coarser grains, smaller grain boundaries, and larger heat affected zone, while finer grain structure, larger grain boundaries, and excellent mechanical properties could be achieved by rapid cooling rate. Shangren et al. [34] also added that weld defects, such as porosity, distortion and hot cracking, easily occurred when arc welding with a high heat input and a low welding speed were used. Moreover, a slightly convex weld profile surface with lower heat input prevents surface shrinkage cracking, which tends to occur in weld zones with higher heat input and concave profile surfaces, because the former surface is subject to lower tensile forces [20].

Weld pool motion has been demonstrated to have a significant effect on centerline solidification crack resistivity $[25,26,36,37]$. Kou and Le [37] proved that a straight weld pool motion generally yields longer centerline solidification cracks, whereas a weaving weld pool motion with tortuous path yields shorter cracks and improved material centerline solidification crack resistivity. This behavior is attributed to the alternating grain orientation formed in the centerline of the weld zone by the weaving technique, which forces the crack to deflect during its propagation along the grain boundaries. Thus, crack energy is consumed, limiting the propagation, and shortening the crack length. Moreover, Kim et al. [36] proved that with the transverse weaving weld profile, a curved liquid film would be formed and it served to suppress the formation of solidification cracks to a significant extent. Biradar and Raman [10] showed that using transverse mechanical arc oscillation changed weld bead morphology and resulted in uniform residual tensile strains around the weld pool, thereby helping to reduce hot cracking tendency.

Weld speed has been studied and shown to have a significant impact on solidification cracking [38-40]. Amaya et al. [38] studied the effect of travel speed on welding low and medium carbon steel and found that solidification cracking susceptibility increased by increasing the weld travel speed, due to the formation of Fe-MnS-FeS eutectic with decreasing solidification temperature. Another study by Ohshita et al. [39] to evaluate solidification cracking when welding low carbon steel with varying weld speed concluded that by using SMAW, solidification cracking never occurred when weld speed is less than the critical level. Albannai et al. [25] proved that welding AA 2024 with high travel speed produced longer centerline solidification cracking due to the formation of sharp centerline on the weld zone. A V-notch surface resulted from tear drop weld pool shape, supporting the initiation and propagation of centerline solidification cracking. Kota et al. [41] stated that the critical strain for solidification cracking decreased with increasing weld speed, which contributed to cracking susceptibility in solidification.

In order to assess the hot cracking resistivity of a material, several tests have been developed and they can be classified into two categories, externally loaded and self-restraint tests as Agrawal [42] presented them and as can be seen in Fig. 3. In externally loaded tests, the load is created externally during the welding process to put the welded material under tensile or bending loads in order to assess and study the material's susceptibility to hot cracking. These tests are good for determining local conditions that lead to cracking, e.g. strain or strain rate. Unfortunately, they are expensive and need special care when setting up. On the other hand, self-restraint or intrinsic tests are designed to be easy in use and are inexpensive, but the strains and stresses generated internally during welding contribute significantly to the initiation and propagation of solidification cracks. Thus, the resultant total crack length is the key to determine material solidification crack susceptibility [42].

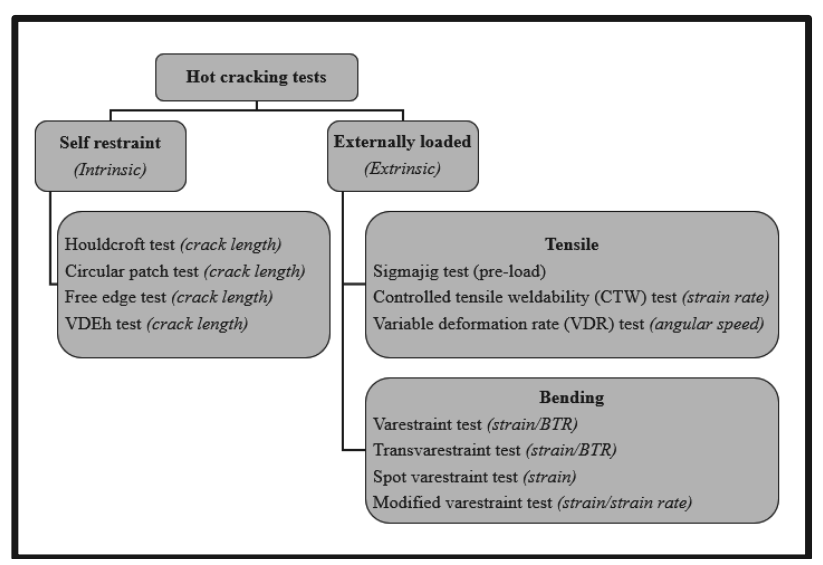

Fig. 3 Classifications of hot cracking tests [42]

As a summary of all previously mentioned literature, several factors induce centerline solidification cracking in a weld metal, e.g. material's susceptible to high solidification temperature range (liquid to solid) $[11,19]$, high thermal and mechanical stresses [20, 21], coarse solidified grain size $[30,31,43]$, straight weld pool motion [10, 36, 37], high heat input (high thermal stress) $[26,32,34,35]$, high weld travel speed $[25,38$, $39]$, weak weld bead shape [20,44], and large and/or long mushy zone $[6,23,24]$. Therefore, it is crucial to overcome the limitations imposed by these factors in order to improve the material's centerline solidification crack resistivity in any fusion weld process. Fig. 4 summarizes the main factors in assisting initiation and/or propagation centerline solidification cracking in fusion welding processes. 
In this study, three different weld pool motions were investigated using gas tungsten arc welding (GTAW): straight, weaving, and tandem. The goal of the study was to investigate the corresponding centerline solidification crack resistivity for autogenous welding of AA2024. Straight and weaving weld pool motions normally depend on a single electrode motion. Tandem motion depends on double electrodes, usually working simultaneously, with one leading the other at a specific distance. Double electrodes have been studied by Schwedersky et al. [45] and show improved productivity when high speed welding on thick joints is needed to form high weld bead quality without discontinuity or humping defects. The novelty of this study lies in the application of a new technique called "tandem GTAW with alternating side-by-side spotlike welds," which forms a straight weld line with a weave-like appearance. The principle of the proposed tandem process is different from that of other tandem processes, because the electrodes are located beside each other at an angle and at a specific distance as they function alternatingly (one at a time semi-stationary) to form high weld bead quality and a weave-like weld profile with lower heat input. All three weld pool motions were subjected to the fishbone test to assess centerline solidification cracking formation and to investigate the above-mentioned crack factors. The aim of this study is to build up better understanding of localized strain around a moving weld pool when comparing three different weld pool motions by studying the total centerline solidification crack lengths and paths, fracture surfaces, thermal stress, and average grain sizes. While, the microstructure behavior and grain structure formation in the weld zone has been studied earlier and proved that tandem technique can be good competitor with promising results to other weld pool motions used in GTAW [25].

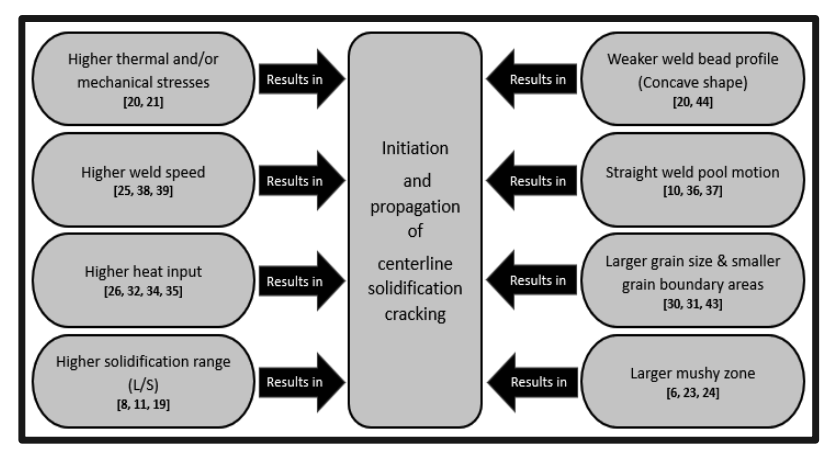

Fig. 4 A diagram summarizing the most important factors affecting solidification crack resistivity as proposed in the mentioned literatures

\section{Experimental setup}

\subsection{Material preparation}

The heat-treatable AA2024 (also known as Al-Cu alloy), widely used in aerospace and structural applications, was investigated. The chemical composition as received commercially of AA2024 alloy and relevant material properties are listed in Table $1 \&$ Table 2 , respectively. AA2024 alloy is highly susceptible to solidification cracking and is not recommended for fusion welding [17]. Improving AA2024 resistivity to centerline solidification cracking would enhance its suitability for fusion welding in more industrial applications.

Tab. 1 Chemical composition of AA2024

\begin{tabular}{lllllllllllll}
\hline Element & $\mathrm{Si}$ & $\mathrm{Fe}$ & $\mathrm{Cu}$ & $\mathrm{Mn}$ & $\mathrm{Mg}$ & $\mathrm{Cr}$ & $\mathrm{Zn}$ & $\mathrm{Ti}$ & $\mathrm{V}$ & $\mathrm{Zr}$ & Other \\
\hline $\mathrm{Wt}[\%]$ & 0.07 & 0.18 & 4.4 & 0.54 & 1.3 & 0.01 & 0.15 & 0.02 & 0.01 & 0.00 & 0.03 \\
\hline
\end{tabular}

Tab. 2 Material properties of $A A 2024$

\begin{tabular}{ll}
\hline Material Properties & Value \\
\hline Density & $2.78(\mathrm{~g} / \mathrm{cc})$ \\
\hline Vickers Hardness & 137 \\
\hline Specific Heat Capacity & $0.875\left(\mathrm{~J} /\left({ }^{\circ} \mathrm{C} \mathrm{g}\right)\right)$ \\
\hline Thermal Conductivity & $121(\mathrm{~W} /(\mathrm{K} \mathrm{m}))$ \\
\hline Solidus Temperature & $505\left({ }^{\circ} \mathrm{C}\right)$ \\
\hline Liquidus Temperature & $638\left({ }^{\circ} \mathrm{C}\right)$ \\
\hline Thermal Expansion & $23.2\left(\mu \mathrm{m} /\left(\mathrm{m}{ }^{\circ} \mathrm{C}\right)\right)$ \\
\hline
\end{tabular}

In this study, three different weld pool motions (straight, weaving, and tandem) were employed autogenously in the GTAW process. Two test specimens for each weld pool motion (six specimens in total) were prepared. Each specimen was sized with a length, width, and thickness of $254 \mathrm{~mm}, 84 \mathrm{~mm}$, and $1.6 \mathrm{~mm}$, respectively. The specimens were prepared using electric discharge machining with a $\pm 0.1 \mathrm{~mm}$ tolerance. These dimensions were chosen following Kou and Le [26, 37], in order to ensure suitability for the fishbone test (Houldcroft test), as shown in Fig. 5. This test is one of the self-restraint tests mentioned earlier and helps to initiate centerline solidification cracking during welding. The total crack length can be easily measured visually, and it is suitable for autogenous welding. Crack initiation was performed using a horizontal slot of $25.4 \mathrm{~mm}$ length and $1 \mathrm{~mm}$ width. Ten vertical slots of $1 \mathrm{~mm}$ width were positioned on each side of the weld line. They were machined to gradually reduce both the strain and tensile stresses during welding and thus, supposedly reduce the total crack length.

The welded samples were cut, ground, polished, and etched with a Keller reagent consisting of $2 \mathrm{~mL}$ of hydrofluoric acid, $3 \mathrm{~mL}$ of hydrochloric acid, $5 \mathrm{~mL}$ of nitric acid, and $190 \mathrm{~mL}$ of distilled water. Optical 
microscope and scanning electron microscopy (SEM) images were obtained and analyzed to understand the material behavior of the solidification process. ImageJ software was used on the uploaded images from the optical microscope to measure the average grain size of the weld zone using the "intercept method".

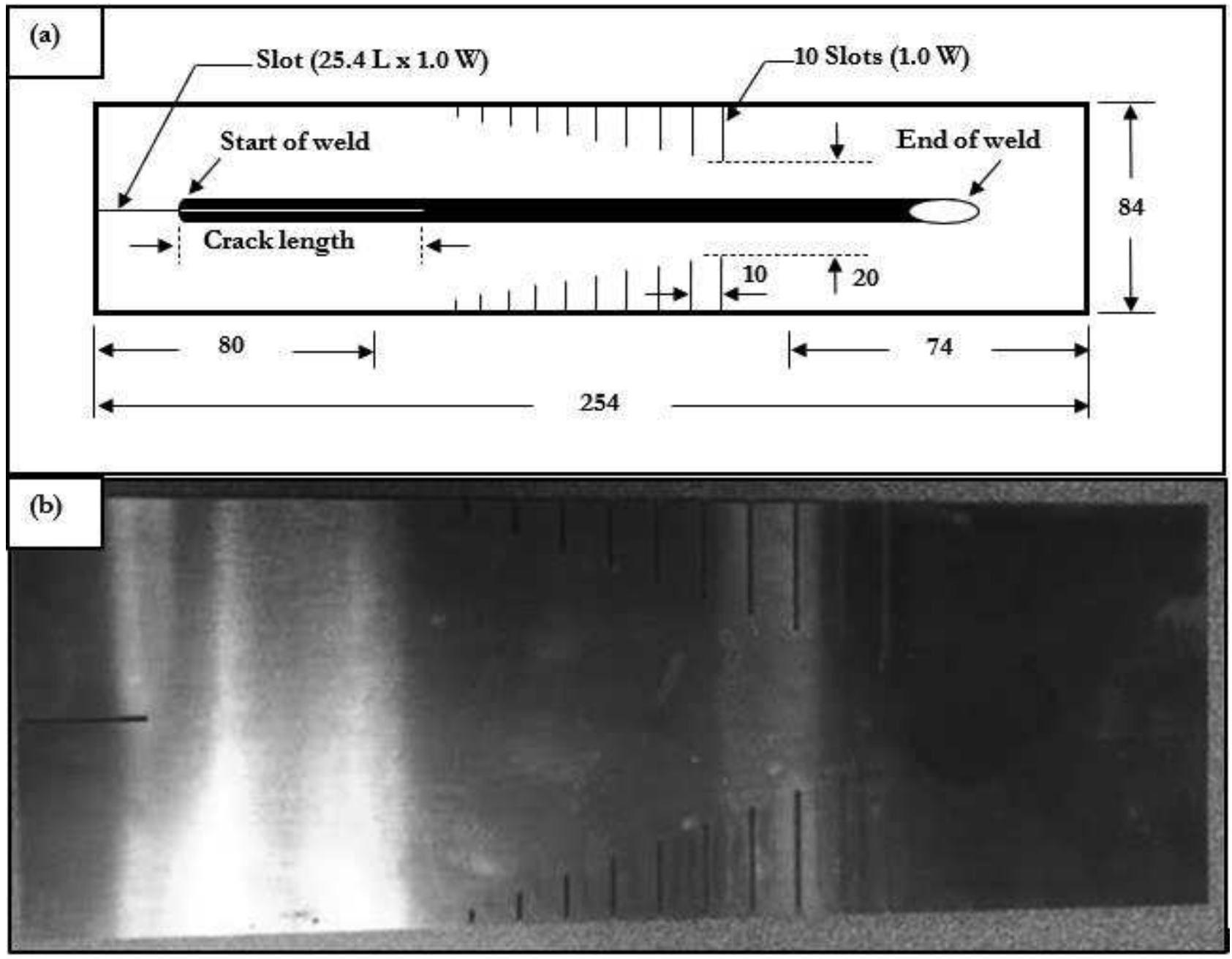

Fig. 5 Schematic of fishbone test specimen used in the experiment (a) schematic of the test sample and dimensions (b) actual prepared test sample of $A A 2024$ (ALL DIM IN MM, $W=$ width and $L=$ length)

\subsection{Welding parameters}

For all investigated weld pool motions, directcurrent straight polarity, and a voltage of $11 \mathrm{~V}$ were used with a $\phi 2.4 \mathrm{~mm}(2 \%$ thoriated) tungsten (W) electrode at a $50^{\circ}$ tip angle. The shielding gas was pure argon $(\mathrm{Ar}, 99.9 \%)$ with a flow rate of $10 \mathrm{~L} / \mathrm{min}$. The longitudinal welding speed for all weld pool motions was $3.6 \mathrm{~mm} / \mathrm{s}$. For the tandem weld pool motion, an average current of $65 \mathrm{~A}$ was used, as shown in Fig. 6, while a fixed $60 \mathrm{~A}$ current was used for the other two weld pool motions. The weaving weld pool motion was performed by mechanical arc oscillation using a robotic arm to form the weaving weld pool motion with an amplitude of $1.9 \mathrm{~mm}$ and frequency of $1 \mathrm{~Hz}$. Note that the current used in the tandem weld pool motion was averaged because each of the two electrodes had a sharp and high start frequency when the arc was struck. The cooling rate and power settings for all weld pool motions are listed in Table 3.

A type- $C$ thermocouple was attached to the back of the welded material and was welded at the center under the weld line by drilling a $0.5 \mathrm{~mm}$ hole, as shown in Fig. 7. The purpose of the thermocouple was to measure the cooling rate from liquidus to solidus temperature (in the mushy zone).

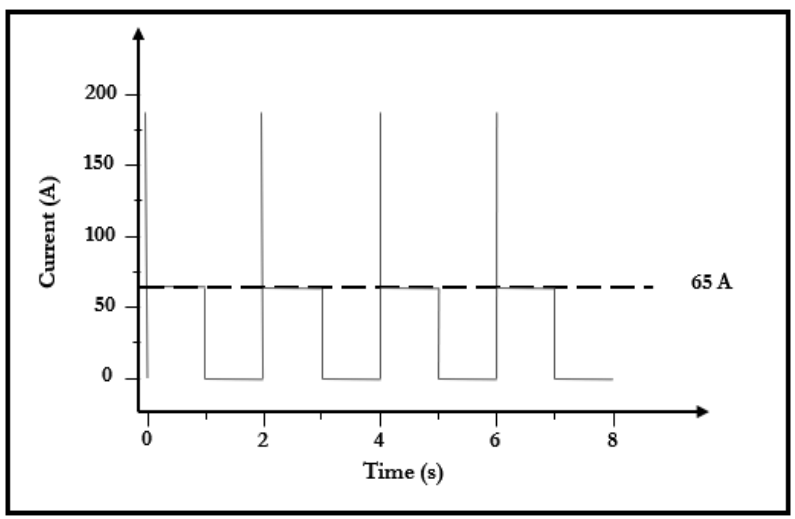

Fig. 6 Average amperage for one electrode in the tandem technique. The horizontal dotted line denotes an average current of $65 A$ 
Tab. 3 Welding parameters and crack results

\begin{tabular}{cccccc}
\hline No. & Weld Pool Motion & Crack Length $(\mathrm{mm})$ & Crack Path & Cooling Rate $\left({ }^{\circ} \mathrm{C} / \mathrm{s}\right)$ & Heat Input $(\mathrm{J} / \mathrm{s})$ \\
\hline 1 & Straight & 137 & Straight & 83.5 & 462 \\
\hline 2 & Weaving & 68 & Tortuous & 127 & 462 \\
\hline 3 & Tandem & 56 & Tortuous & 175 & 508 \\
\hline
\end{tabular}

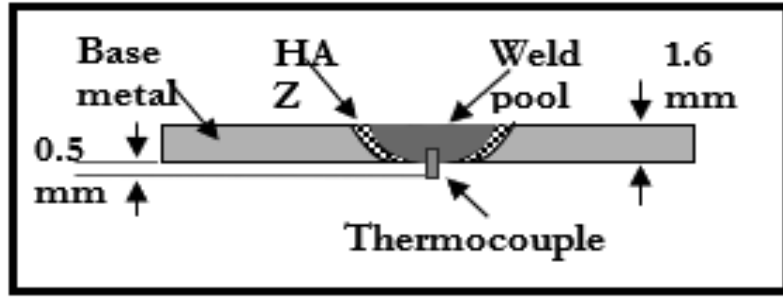

Fig. 7 Thermocouple location

\subsection{The proposed method}

To achieve the tandem weld pool motion for the proposed tandem GTAW with alternating side-byside spot-like welds (semi-stationary welds), two electrodes were aligned side-by-side at a $30^{\circ}$ angle in a torch fixture, and an external argon gas cylinder was connected to the fixture to allow continuous gas flow inside the torch fixture to surround the electrodes during the welding process. The distance between the two electrode tips was $3.8 \mathrm{~mm}$, which implied an amplitude of $1.9 \mathrm{~mm}$ for each electrode (Fig. 8). Each electrode was connected to an independent GTAW power source. A microelectronic Arduino board was used to control the welding time for each electrode, to ensure accurate and symmetric spot-like welds that overlapped without arc interference. Each electrode operated for 1 second and was then deactivated, allowing the other electrode to work for the next second. This process was repeated until the entire weld line had been deposited longitudinally, as shown in Fig. 9 for the schematic tandem process and Fig. 10 for actual resultant weld bead deposited on the plate with the tandem process.

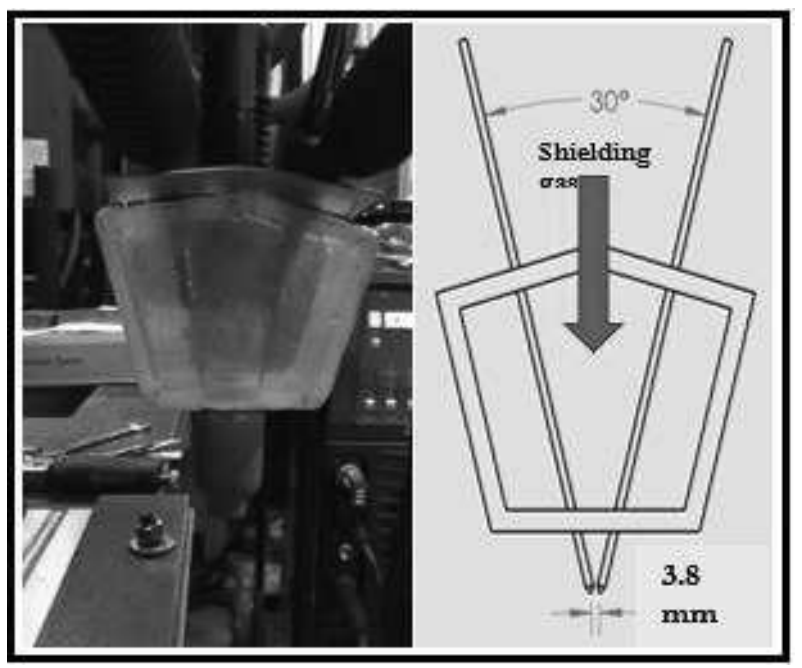

Fig. $\boldsymbol{8}$ Actual custom-made torch fixture on the left, and schematic electrode angle and distance in custom-made torch on the right

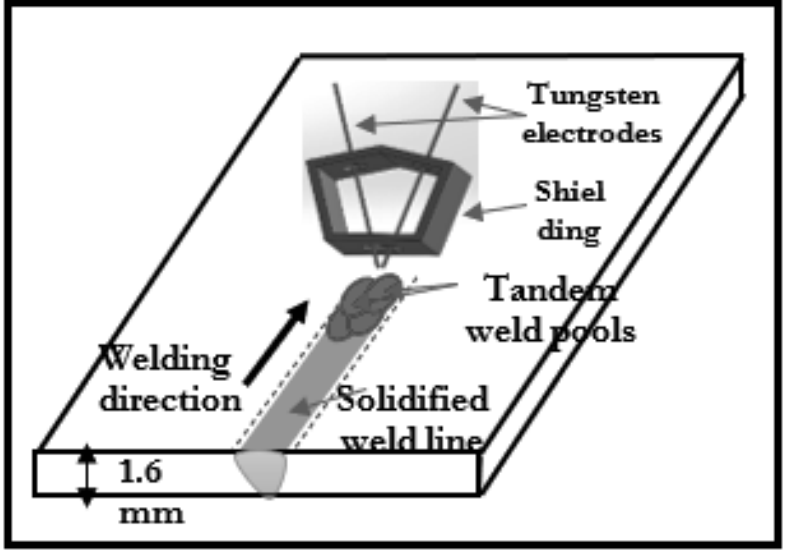

Fig. 9 Schematic of weld pools produced using the proposed tandem GTAW with alternating side-by-side spot-like welds

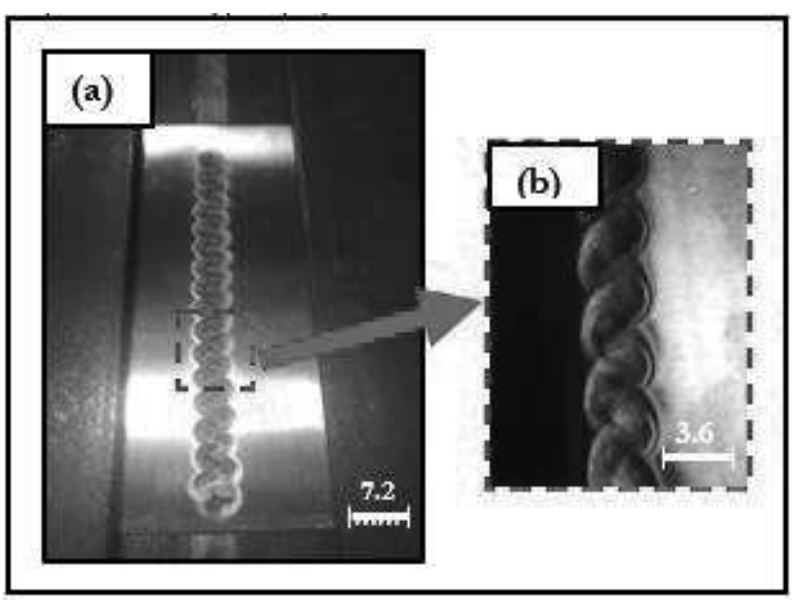

Fig. 10 Images of weld line produced using the proposed tan$\operatorname{dem} G T A W$ with alternating side-by-side spot-like welds a) lower magnification b) bigher magnification

\section{Results and discussion}

\subsection{Total centerline solidification crack lengths}

The average centerline crack length results (for two samples) and path for each weld pool motion are listed in Table 3. Note that the longest average total crack length was $137 \mathrm{~mm}$, obtained with the straight weld pool motion. The shortest average total crack length was $56 \mathrm{~mm}$, obtained with the proposed tandem weld pool motion. Thus, a reduction of approximately $60 \%$ was achieved by the tandem technique over the straight weld pool motion. Similarly, the weaving weld pool motion exhibited good reduction in the total average crack length, with $50 \%$ compared to the straight-line case. The following discussion and results will clarify the reasons for the best improvement in total crack length achieved by tandem technique 
among all three presented techniques.

Although the weaving weld pool motion exhibited good reduction in total crack length, in agreement with the findings of Biradar and Raman [10] and Kou and Le $[26,37]$, the tandem motion exhibited superior performance, with an approximate $17 \%$ reduction compared to the crack produced by the weaving weld pool motion (Table 3). Moreover, the crack yielded by the proposed tandem weld pool motion had a tortuous path similar to that produced by the weaving weld pool motion, as shown in Fig. 11. This result indicates that the proposed method changed the behavior and orientation of the solidified grains and acted almost like weaving weld pool. Hence, the crack changed course in an attempt to follow the columnar dendritic grain boundaries, inducing crack energy consumption and yielding a shorter longitudinal centerline crack length compared to that with the straight crack. This approach was also in good agreement with Ragavendran and Vasudevan [35], who stated that with finer grain structure the higher amount of grain boundaries result in higher toughness and strength due to more interfaces where dislocations pile up and make a tortuous path for cracks to propagate.
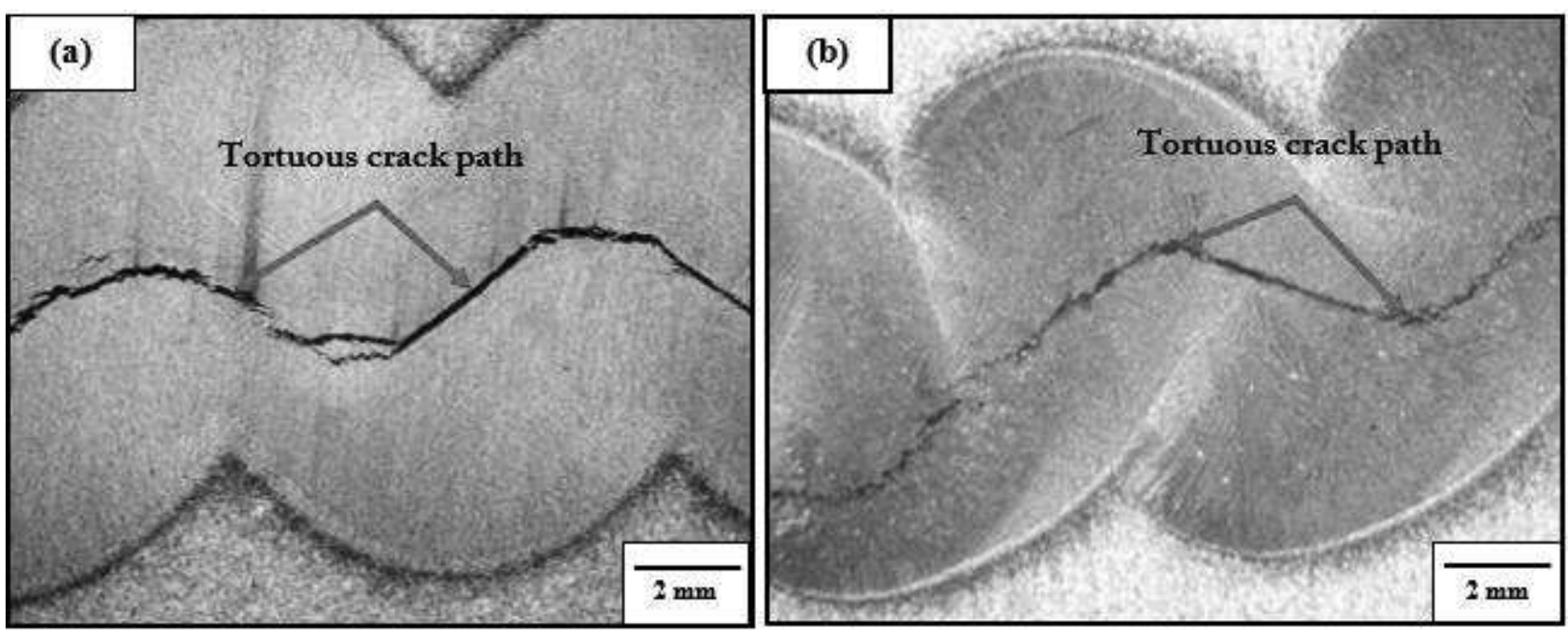

Fig. 11 Optical macroscopic images (top view) of tortuous centerline cracks yielded by the (a) weaving and (b) proposed tandem welding techniques

\subsection{Heat input and cooling rate}

The heat input and cooling rate have a direct impact on the grain size, thermal stress, fracture surface, and total centerline solidification crack length. Generally, the cracking response is promoted by increasing the heat input when welding aluminum alloys $[18,34]$. Moreover, changing the weld pool shape and stress distribution at the trailing edge (mushy zone) of the weld pool affects the material response to the crack $[21,46]$.

Table 3 lists the cooling rates for all three different weld pool motions. The highest and lowest cooling rates of $175^{\circ} \mathrm{C} / \mathrm{s}$ and $83.5^{\circ} \mathrm{C} / \mathrm{s}$ were obtained for the tandem and straight weld pool motions, respectively (thermocouple readings). The heat input was calculated using Equation (1), which was employed by Min et al. [47] to study the effect of heat input during the GTAW process on the microstructure and mechanical properties of AZ61 Mg alloy.

$$
\text { Heat Input }=\frac{A \times V \times \eta}{S}
$$

Where:

A...Welding current produced by the welding machine [Ampere],
V...Voltage depending on the gap between the electrode tip and welded material surface [Volt], $\eta$...Arc efficiency [70\%] following Norman et al. study [48],

S...Welding speed $[\mathrm{mm} / \mathrm{sec}]$.

The most interesting aspect of Table 3 is that, although the tandem method in conjunction with the welding power input should have lowered the cooling rate, it did not. This unusual behavior may have arisen because of the arc deactivation and operation of another arc at a different location at some distance. Hence, the weld covered a larger area and the power density was reduced, which distributed the heat and lowered the total heat input. Therefore, the proposed tandem weld pool motion has lower heat input and, thus, lower residual stresses should result as mentioned earlier [26]. Although the calculated power input for the tandem weld pool motion was the highest among the three considered motions, the cooling rate was fast (i.e. from the thermocouple measurement). In regular welding (continuous arc), a high-power input should yield a slow cooling rate and higher heat input [18]. However, this relationship did not manifest in tandem case because of the distance between the spots 
during the alternation of both arcs as the entire weld was deposited. As mentioned above, the mismatch between the power input and cooling rate resulted from alternate activation and deactivation of both arcs on different spots. The rapid cooling rate obtained by tandem technique is believed to be mandatory for producing finer grain structure and agreed with Ragavendran and Vasudevan [35]. It should be noted that the tandem technique is taking the advantages of spot like welds (semi-stationary welds) and the overlap distance at the same time, with each weld pool depending on the following one. This action ensures lower heat input and less tensile strain at the same time, which normally in a single spot weld would result in high tensile strain due to the rapid shrinkage around the weld pool caused by rapid solidification of dendrite tips. Although, the single spot weld encountered high tensile strain, a single weld pool can also generates large tensile residual stresses behind the weld pool [40]. In tandem weld pool motion, however, the two weld pools reduce the localized tensile stress, because one weld pool affects the other and converts some of the tensile stress to compression stress as shown in Fig. 12. This result exhibits good agreement with Ploshikhin et al. [49], when they proved that additional laser beam moving parallel to the main laser beam decreases the accumulated strain and the displacement in a crack critical region.

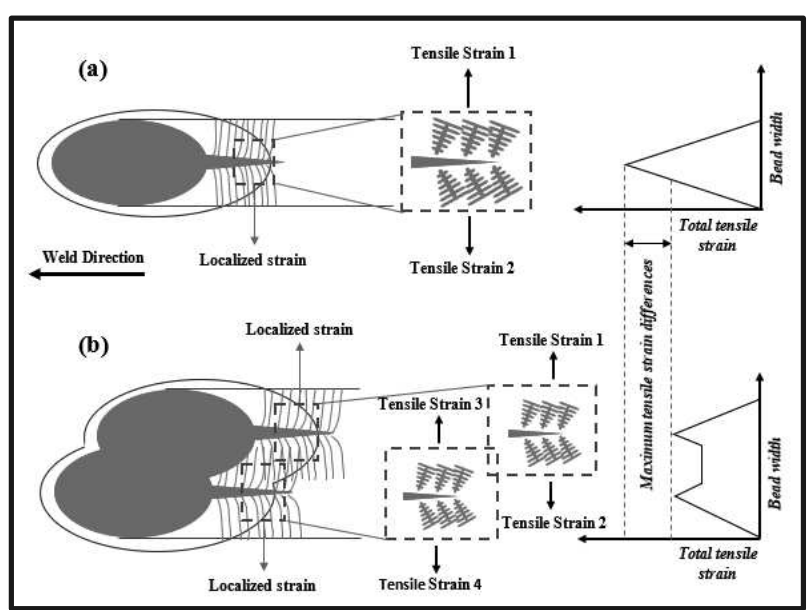

Fig. 12 Schematic of localized strain points in the mushy zone of (a) single weld pool and (b) tandem process

So, in the tandem technique when one weld pool is trying to solidify rapidly after shutting off the first electrode, the second electrode starts the arc directly with overlap distance and manipulating the strains around the previous weld pool with braking or re-melting the columnar dendrite and splitting the localized strain as shown in Fig. 12. While in single weld pool motion Fig. 12(a), the magnitudes of tensile strains 1 and 2 will reach higher maximum stress concentration on one localized point, in the tandem process Fig. 12(b) shows that tensile strains 2 and 3 almost cancel each other due to overlapping weld pools beside each other and the resulting maximum stress concentration would be lower in comparison with that in a single weld pool. Moreover, the tandem process showed two different stress concentration points and they are not in the centerline of the generally produced weld zone. Thus, this approach is believed to be a factor in assisting a tortuous crack path that results in better resistance to centerline solidification cracking.

Further evidence that the proposed tandem weld pool motion produces lower heat input and is superior to the other two alternatives is shown by the weld profile. However, there are some limitations to the proposed technique such as process setup, weld parameters optimization and two weld machines are needed. Fig. 13 shows transverse view of the weld profiles obtained for all three weld pool motions used in this study. Note that the proposed technique allowed almost no concavity $(0.1 \mathrm{~mm})$ with almost flat weld profile and small angle of incline, as shown in Fig. 13(e) and (f). Concave shapes (vertical distance from the shoulder of the base metal to the centerline of the weld) of 0.5 and $0.6 \mathrm{~mm}$ with a medium angle incline and steeper incline were observed when welding was performed using the straight and weaving weld pool motions, as shown in Fig. 13(a)-(d) respectively. As mentioned above, concave profiles usually have a negative impact on centerline solidification cracking under high heat input and high stress concentration [20]. Thus, the weld profiles indicate that the thermal stress around the weld centerline is much lower for tandem weld pool motion compared with the other two weld pool motions.

Furthermore, the thermal stress and heat input during the weld process influence the fracture surface [49]. Fig. 14 shows SEM images of the centerline solidification cracking fracture surfaces obtained for the three weld pool motions. For the straight weld pool motion, the fracture surface exhibits axial dendritic grains (Fig. 14(a)). Thus, the high heat input with the weld pool motion was sufficient for formation of this structure type, allowing the crack to initiate and propagate easily through the grain boundaries at the weld centerline where the dendritic grains formed straight lines creating a plane of weakness in agreement with both [48, 50]. Fig. 14(b) and (c) for the weaving and tandem weld pool motions, respectively, show no evidence of axial dendritic grains because of different weld pool motions, while grain size and orientation show lower heat inputs when compared to the straight motion. The fracture surfaces for both the tandem and weaving weld pool motions indicate comparable heat input and thermal stress. The fracture surface for the weaving weld pool motion is smoother and indicates higher thermal stress, which caused the crack to appear in the early stages of the solidification process with the appearance of higher fraction eutectic at 
higher temperature and earlier solidification stage. For the tandem technique, the crack occurred at a later stage showing rougher fracture surface, with finer grains at lower fraction eutectic and temperature. This finding is in good agreement with Zhang et al. [51].

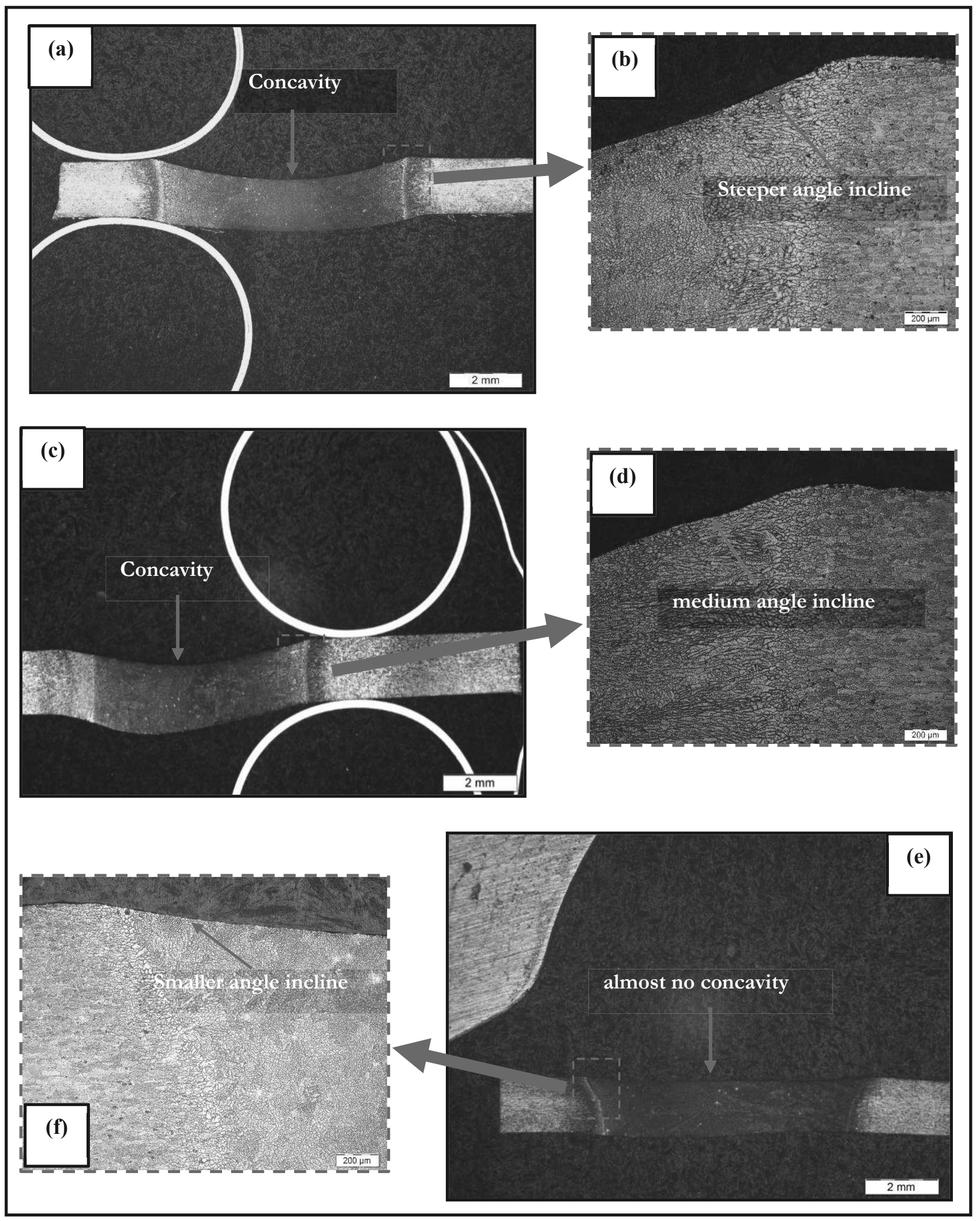

Fig. 13 Optical macroscope and microscope images of the transverse view: (a and b) straight, (c) and (d) weaving, and (e and f) tandem weld pool motion profiles showing concavities of approximately $0.6,0.5$, and $0.1 \mathrm{~mm}$, respectively 

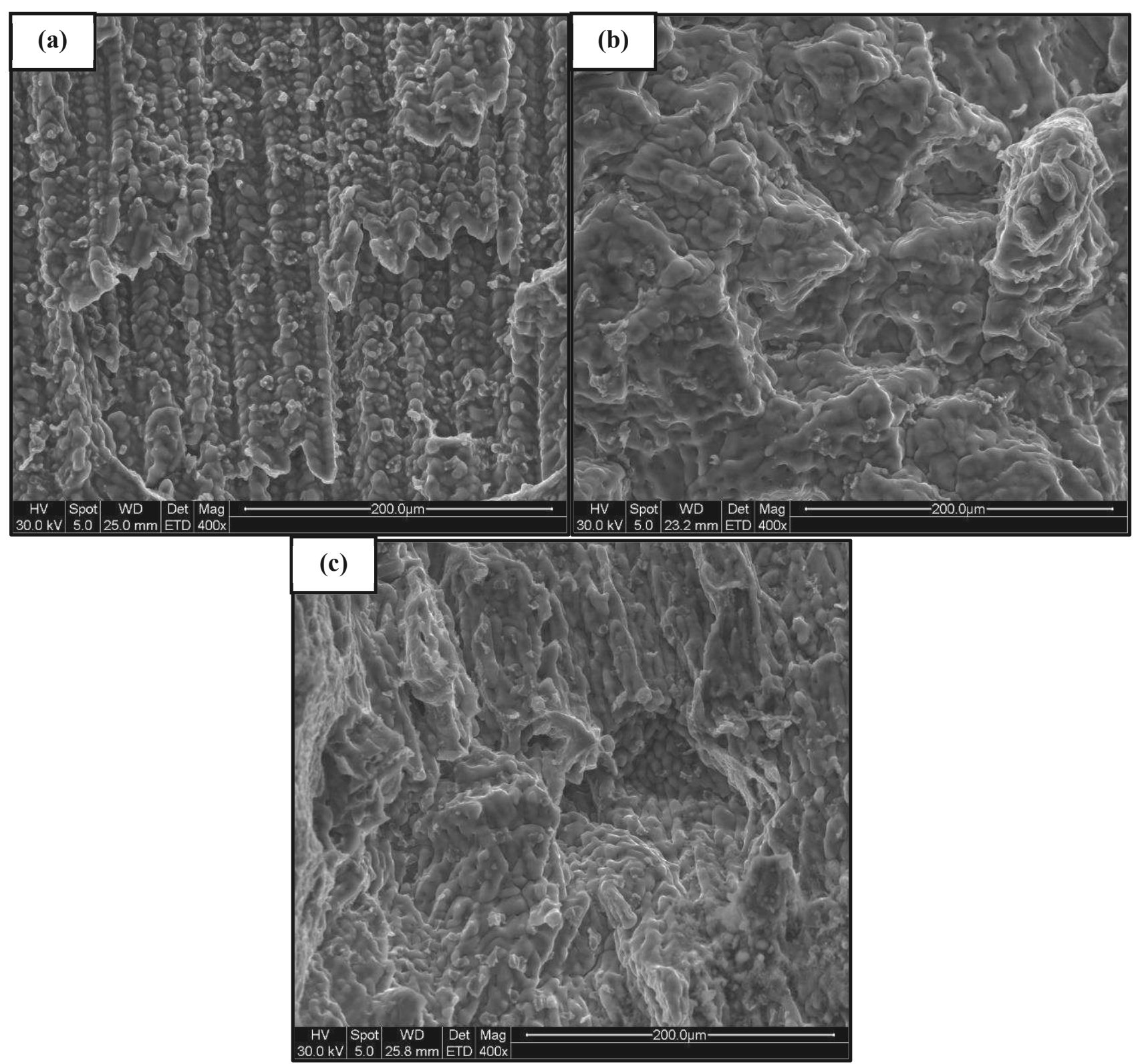

Fig. 14 SEM images showing fracture surfaces of centerline solidification cracking for (a) straight, (b) weaving, and (c) tandem weld pool motions

The average grain size of the weld zone was measured, and the results are shown in Fig. 15 A clear comparison exists between the average grain size and total centerline crack length for the three weld pool motions studied in this work. Hence, it is apparent that shorter total centerline solidification cracking is achieved with finer average grain size, which is in agreement with Kou [20] and Ragavendran and Vasudevan [35]. Additionally, Fig. 15 shows that the tandem weld pool motion reduced the grain size by $52 \%$ and produced fine grains of $10 \mu \mathrm{m}$, while the straight weld pool which produced an average grain size of $21 \mu \mathrm{m}$. The weaving weld pool motion yielded an average grain size of $15 \mu \mathrm{m}$, with only $28 \%$ improvement over the straight case. In addition, the fracture surface for the tandem weld pool motion (Fig. 14(c)) exhibited mostly finer grain size compared with that for the weaving motion (Fig. 14(b)), indicating that the tandem weld pool motion has lower heat input and a higher cooling rate. We believe that the melt flow process in tandem technique affected the columnar grains in the mushy zone, causing a large number of columnar grains to break or re-melt, which repressed the growth of the columnar grains and offered a large amount of grain nucleus and finer grain formation, in agreement with Shangren et al. [34].

Overall, the results for the weaving weld pool motion indicated lower heat input, lower thermal stress, and shorter total centerline solidification cracking than those for the straight weld pool motion, which has also been proven by Hu et al. [52]. However, the tandem weld pool motion yielded better results, with improvements heat input, thermal stress, average grain size, and total centerline crack length. 


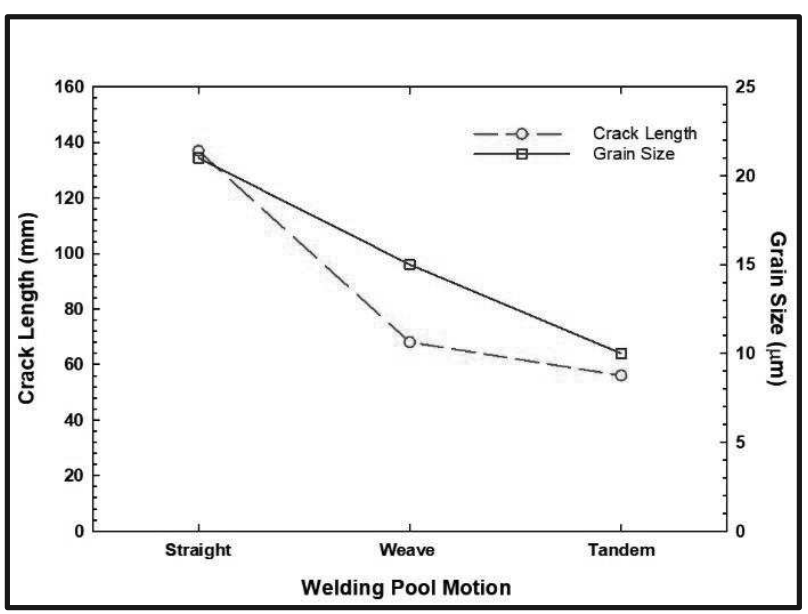

Fig. 15 Centerline solidification crack length vs. average grain size for the three investigated weld pool motions

\section{Conclusions}

The proposed technique is superior to the straight and weave weld pool motions however, there are some limitations such as process setup, weld parameters optimization and two weld machines are needed. The results of current investigation can be summarized as follows:

- A total crack length reduction of approximately $60 \%$ was achieved for the tandem weld pool motion over the straight case. The weaving weld pool motion exhibited a 50\% reduction in total crack length compared with the straight technique.

- The tandem weld pool motion yielded a tortuous path, which proves that the proposed method changed the orientation of the solidified grains and caused crack deflection that attempted to follow the columnar grain boundaries.

- Even though the same welding parameters were used for all the techniques, lower heat input and higher cooling rate were obtained because of the arc deactivation and operation of another arc at a different location at some distance for the tandem weld pool motion.

- The localized centerline thermal stresses for both the straight and weaving weld pool motions were greater than that for the tandem technique due to severely concave weld profile shapes, which assisted the initiation and propagation of the centerline solidification cracking.

- The fracture surface obtained for the tandem weld pool motion confirmed improvements in grain refinement, thermal stress, and total centerline solidification crack length as a result of the lower heat input.

Future studies will focus on assessing the effects of the angles and distance between the electrodes on the outcome to find the optimum electrode locations. Moreover, numerical heat transfer modeling should be implemented to investigate the fluid and heat flows in the weld pool.

\section{Acknowledgement}

We are grateful to Avraham Benatar, David Phillips, John Lippold, Dave Farson, Wei Zhang, and Boian Alexandrov for their enriching discussions through this research. We also thank Guilherme Abreu Far for his help with the electronic components of our experiments. Additional support was provided by the staff at the Ohio State University laboratories, especially Ed Pfeifer, Sebastian Romo, and Gaofeng Sha.

\section{References}

[1] GENG, S., PING J., LINGYU G., XUESONG G., GAOYANG M. (2020). Multi-scale simulation of grain/sub-grain structure evolution during solidification in laser welding of aluminum alloys. International Journal of Heat and Mass Transfer 149:119252. ISSN 0017-9310

[2] KOU, S. (2003). Welding Metallurgy. 2nd Edition ed. INC., Publication, New Jersey: John Wiley \& Sons. ISBN 0-471-43491-4

[3] CONIGLIO, N., CROSS, C. (2013). Initiation and growth mechanisms for weld solidification cracking. International materials reviews 58 (7):375397. ISSN 0950-6608

[4] WELLER, D., HAGENLOCHER, C., WEBER, R., GRAF, T. (2020). Influence of the solidification path of AlMgSi aluminium alloys on the critical strain rate during remote laser beam welding. Science and Technology of Welding and joining 25 (2):101-105. ISSN 1362-1718

[5] BODAGHI, F., MOVAHEDI, M., KOKABI, A., TAVAKOLI, R. (2019). Effect of solid fraction, grain misorientation and grain boundary energy on solidification cracking in weld of $\mathrm{Al}-\mathrm{Cu}$ aluminum alloys. Materials Research Express 6 (8):086598. ISSN 2053-1591

[6] AGARWAL, G., KUMAR, A., RICHARDSON, I., HERMANS, M. (2019). Evaluation of solidification cracking susceptibility during laser welding in advanced high strength automotive steels. Materials \& Design 183:108104. ISSN 0264-1275 
[7] GHAINI, F., SHEIKHI, M., TORKAMANY, M., SABBAGHZADEH, J. (2009). The relation between liquation and solidification cracks in pulsed laser welding of 2024 aluminium alloy. Materials Science and Engineering: A 519 (1-2):167171. ISSN 0921-5093

[8] LIPPOLD, J. (2015). Welding metallurgy and weldability: Wiley Online Library. ISBN 1118230701

[9] KOU, S. (2020). Welding Metallurgy. 3rd Edition ed: John Wiley \& Sons. ISBN: 978-1-11952481-6

[10] BIRADAR, N., RAMAN, R. (2012). Investigation of hot cracking behavior in transverse mechanically arc oscillated autogenous AA2014 T6 TIG welds. Metallurgical and Materials Transactions A 43 (9):3179-3191. ISSN 2053-1591

[11] ALIZADEH-SH, M., MARASHI, S., RANJBARNODEH, E., SHOJA-RAZAVI, R., OLIVEIRA, J. (2020). Prediction of solidification cracking by an empirical-statistical analysis for laser cladding of Inconel 718 powder on a non-weldable substrate. Optics \& Laser Technology 128:106244. ISSN 0030-3992

[12] ZACHARIA, T. (1994). Dynamic stresses in weld metal hot cracking. Welding Journal Including Welding Research Supplement 73 (7):164-172. ISSN 0043-2296

[13] CROSS, C., TACK, W., LOECHEL, W., KRAMER, S. (1990). Aluminum weldability and hot tearing theory. Weldability of Materials:275-282.

[14] MSOMI, V., MBANA, N. (2020). Mechanical Properties of Friction Stir Welded AA1050H14 and AA5083-H111 Joint: Sampling Aspect. Metals 10 (2):214.

[15] SOYSAL, T., KOU, S. (2019). Effect of filler metals on solidification cracking susceptibility of $\mathrm{Al}$ alloys 2024 and 6061. Journal of Materials Processing Technology 266:421-428. ISSN 09240136

[16] KHALILABAD, M., et, al. (2018). Effect of tool geometry and welding speed on mechanical properties of dissimilar AA2198-AA2024 FSWed joint. Journal of Manufacturing Processes 34:86-95. ISSN 1526-6125

[17] LIU, J., KOU, S. (2017). Susceptibility of ternary aluminum alloys to cracking during solidification. Acta Materialia 125:513-523. ISSN 1359-6454

[18] ÇAM, G., İPEKOĞLU, G. (2017). Recent developments in joining of aluminum alloys. The International Journal of Advanced Manufacturing Technology 91 (5-8):1851-1866. ISSN 1433-3015
[19] PUMPHREY, W., JENNINGS, P. (1948). A consideration of the nature of brittleness at temperatures above the solidus in castings and welds in aluminium alloys. J. of the Inst. of Metals 75:235-256.

[20] KOU, S. (2003). Solidification and liquation cracking issues in welding. Jom 55 (6):37-42. ISSN 1543-1851

[21] CROSS, C. (2005). On the origin of weld solidification cracking. In Hot cracking phenomena in welds, 3-18. Springer.

[22] CONIGLIO, CROSS, C. (2020). Effect of weld travel speed on solidification cracking behavior. Part 1: weld metal characteristics. The International Journal of Advanced Manufacturing Technology $107 \quad$ (11):5011-5023. doi: 10.1007/s00170-020-05231-y. ISSN 1433-3015

[23] GRANGE, D., BARTOUT, D., MACQUAIRE, B., COLIN, C. (2020). Processing a non-weldable Nickel-base superalloy by Selective Laser Melting: role of the shape and size of the melt pools on solidification cracking. Materialia:100686. ISSN 2589-1529

[24] WANG, X., et al. (2014). Analysis of solidification cracking susceptibility in side-by-side dualbeam laser welding of aluminum alloys. The International Journal of Advanced Manufacturing Technology 73 (1-4):73-85. ISSN 0268-3768

[25] ALBANNAI, A., ALORAIER, A., ALASKARI, A., ALAWADHI, M. (2019). Improving Centerline Solidification Crack Resistivity of AA 2024 Using Tandem Side-by-Side GTAW Technique. Materials Performance and Characterization 8 (4). ISSN 2379-1365

[26] KOU, S, LE, Y. (1985). Grain structure and solidification cracking in oscillated arc welds of 5052 aluminum alloy. Metallurgical Transactions $A$ 16 (7):1345-1352. ISSN 1543-1940

[27] SOYSAL, T., KOU, S. (2018). A simple test for assessing solidification cracking susceptibility and checking validity of susceptibility prediction. Acta Materialia 143:181-197. ISSN 1359-6454

[28] KONADU, D., PISTORIUS, P., TOIT, M. (2019). The influence of Ti and Nb on solidification cracking of ferritic stainless steels, as determined using self-restrained samples. Welding in the World 63 (5):1163-1172. ISSN 1878-6669

[29] SHINOZAKI, K., et al. (2018). Arc characteristic evaluation of the double-electrode GTAW process using high current values. The International Journal of Advanced Manufacturing Technology 98 (1-4):929-936. ISSN 0288-4771

[30] HAGENLOCHER, C., et al., Reduction of the hot cracking susceptibility of laser beam welds in AlMgSi 
alloys by increasing the number of grain boundaries. Science and Technology of Welding and joining, 2019. 24(4): p. 313-319.

[31] AGARWAL, G., et al. (2018). Study of solidification cracking susceptibility during laser welding in an advanced high strength automotive steel. Metals 8 (9):673.

[32] DAVIES, J., GARLAND, G. (1975). Solidification structures and properties of fusion welds. International metallurgical reviews 20 (1):83108. ISSN 0367-9020

[33] LAMPMAN, S. (1997). Weld integrity and performance: a source book adapted from ASM international handbooks, conference proceedings, and technical books: Asm International. ISBN 1615032045

[34] LI, S., GAOYANG M., CHUNMING W. (2020). A study on laser beam oscillating welding characteristics for the 5083 aluminum alloy: Morphology, microstructure and mechanical properties. Journal of Manufacturing Processes 53:12-20. ISSN 1526-6125

[35] RAGAVENDRAN, M., VASUDEVAN, M. (2020). Laser and hybrid laser welding of type 316L (N) austenitic stainless steel plates. Materials and Manufacturing Processes 35 (8):922-934. ISSN 1042-6914

[36] KIM, C., KANG, M., KANG, N. (2013). Solidification crack and morphology for laser weave welding of Al $5 J 32$ alloy. Science and Technology of Welding and joining 18 (1):57-61. ISSN 1362-1718

[37] KOU, S., LE, Y. (1985). Alternating grain orientation and weld solidification cracking. Metallurgical Transactions A 16 (10):1887-1896. ISSN 0360-2133

[38] AMAYA, T., YONEZAWA, T., OGAWA, K., PELTONEN, J., HÄNNINEN, H. (2018). Solidification Cracking Mechanism of Carbon Steel Weld Metal. Welding Journal 97 (2):55S64S.

[39] OHSHITA, S., YURIOKA, N., MORI, N., KIMURA, T. (1983). Prevention of solidification cracking in very low carbon steel welds. WELDING J. 62 (5):129.

[40] SAVAGE, F., LUNDIN, D. (1968). The Evaluation of the Weldability of Structural Alloys with the Varestraint Test. RENSSELAER POLYTECHNIC INST TROY NY WELDING LAB.

[41] KADOI, K., et al. (2013). The effect of welding conditions on solidification cracking susceptibility of type $310 \mathrm{~S}$ stainless steel during laser welding using an in-situ observation technique.
Welding in the World 57 (3):383-390. doi: 10.1007/s40194-013-0023-9. ISSN 1878-6669

[42] AGARWAL, G. (2019). Study of solidification cracking during laser welding in advanced high strength steels: A combined experimental and numerical approach. Delft University of Technology.

[43] TANG, Z., VOLLERTSEN, F. (2014). Influence of grain refinement on hot cracking in laser welding of aluminum. Welding in the World 58 (3):355-366. ISSN 1878-6669

[44] KUMAR, H., SOMIREDDY, A., GURURAJ, K. (2012). A review on critical aspects of 316ln austenitic stainless steel weldability. Int. J. Mat. Sci. App 1:1.

[45] SCHWEDERSKY, B., et al. (2018). Arc characteristic evaluation of the double-electrode GTAW process using high current values. The International Journal of Advanced Manufacturing Tecbnology 98 (1-4):929-936. ISSN 1433-3015

[46] GOODWIN, M. (1988). The effects of heat input and weld process on hot cracking in stainless steel. Welding Journal 67 (4):88-94.

[47] MIN, D., SHEN, J., LAI, S., CHEN, J. (2009). Effect of heat input on the microstructure and mechanical properties of tungsten inert gas arc butt-welded AZ61 magnesium alloy plates. $M a-$ terials Characterization 60 (12):1583-1590. ISSN 1044-5803

[48] NORMAN, F., DRAZHNER, V., PRANGNELL, B. (1999). Effect of welding parameters on the solidification microstructure of autogenous TIG welds in an $\mathrm{Al}-\mathrm{Cu}-\mathrm{Mg}-\mathrm{Mn}$ alloy. Materials Science and Engineering: A 259 (1):53-64. ISSN 0921-5093

[49] PLOSHIKHIN, V., PRIHODOVSKY, A., ILIN, A. (2011). Experimental investigation of the hot cracking mechanism in welds on the microscopic scale. Frontiers of Materials Science 5 (2):135. ISSN 2095-025X

[50] REDDY, M., GOKHALE, A., RAO, P. (1997). Weld microstructure refinement in a 1441 grade aluminium-lithium alloy. Journal of Materials Science 32 (15):4117-4126. ISSN 1573-4803

[51] ZHANG, Y., et al. (2015). Reduced hot cracking susceptibility by controlling the fusion ratio in laser welding of dissimilar $\mathrm{Al}$ alloys joints. Journal of Materials Research 30 (7):993-1001. ISSN 0884-2914

[52] HU, J-F., et al. (2006). Numerical simulation on temperature and stress fields of welding with weaving. Science and Technology of Welding and joining 11 (3):358-365. ISSN 1362-1718 